\title{
An overview of decadal-scale \\ sea surface temperature variability in the \\ observational record
}

\section{Clara Deser, Adam Phillips}

doi: $10.22498 /$ pages.25.1.2

\author{
National Center for Atmospheric Research, Boulder, USA
}

\section{Introduction}

Due to their thermal and mechanical inertia, the oceans play a key role in decadal-scale climate variability (DCV) and provide a potential source of initial-value predictability for low-frequency climate fluctuations. Characterizing oceanic DCV is challenging, however, due to the limited duration of the observational record combined with the sparse and irregular data coverage. These constraints also hinder assessments of the robustness of the patterns and timescales of DCV, and understanding of the governing mechanisms. In this brief note, we provide an overview of the main phenomena of DCV in the historical sea surface temperature (SST) data record, discuss proposed interpretations and causal mechanisms, and highlight outstanding research questions.

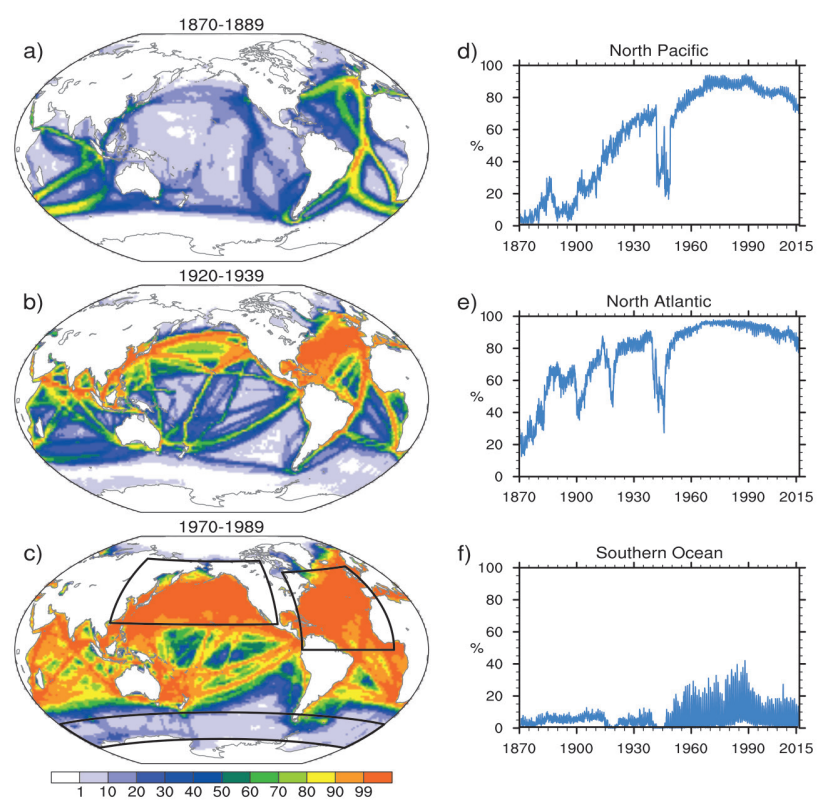

Figure 1: Distribution of sea surface temperature observations from the International Comprehensive Ocean Atmosphere Data Set. Maps show the percentage of months with at least one measurement in a 2 degree latitude by 2 degree longitude grid box during (a) 1870-1899, (b) 1920-1939, and (c) 19701989. Timeseries (1870-2015) show the percentage of grid boxes that have at least one observation per month within the regions outlined in Fig. 1c. (d) North Pacific $\left(20^{\circ}-70^{\circ} \mathrm{N}\right.$, $\left.110^{\circ} \mathrm{E}-100^{\circ} \mathrm{W}\right),\left(\right.$ e) North Atlantic $\left(0^{\circ}-60^{\circ} \mathrm{N}, 80^{\circ} \mathrm{W}-0^{\circ} \mathrm{W}\right)$, and (f) Southern Ocean $\left(50^{\circ}-70^{\circ} \mathrm{S}, 0^{\circ} \mathrm{W}-360^{\circ} \mathrm{E}\right)$.

\section{SST data coverage}

Our focus on SST is motivated by both practical and physical considerations. On the practical side, the longest ocean temperature records are measured near the surface from ships-of-opportunity, starting with bucket samples in the $19^{\text {th }}$ and early $20^{\text {th }}$ centuries followed by engine-intake measurements (e.g., Woodruff et al., 2008). On the physical side, SSTs are the main agent of communication between the atmosphere and the ocean, and thus represent a key quantity for probing DCV (for a discussion of the upper-ocean mixed layer heat budget, c.f. Deser et al., 2010).

Fig. 1 (left column) shows maps of SST data coverage based on the International Comprehensive Ocean Atmosphere Data Set (ICOADS) (Woodruff et al., 2008) during three representative 20-year periods spanning the late 19th and 20th centuries: 1870-1899, 1920-1939, and 1970-1989. These maps show the percentage of months with at least one measurement in a $2^{\circ}$ latitude by $2^{\circ}$ longitude grid box in the 20 -year period indicated. We note that the instrumental coverage falls off rapidly before 1870 , and that satellites provide nearly global coverage starting in the 1980s (see Woodruff et al., 2008 and Deser et al., 2010). The discrete outlines of commercial shipping routes and their changes over time are readily apparent, especially in the earlier time periods (Fig. 1). Broadly speaking, the North Atlantic, western South Atlantic, and northern Indian Ocean contain the highest density of observations, with reasonable coverage back to approximately 1870 . Data coverage in the North Pacific is limited before about 1920, in the Tropics before about 1960, and in the Southern Ocean before the advent of satellite remote sensing (Fig. 1). The uneven and changing spatial coverage of SST measurements from historical ship-based archives must be taken into account in any analysis of DCV. Further information on the spatiotemporal coverage of other SST data sets is available at climatedataguide.ucar.edu.

\section{The main phenomena of DCV}

In our view, there is no unique "best" approach to defining the main phenomena of DCV. Here, we adopt a basin-specific perspective, which has the advantage that 
any inter-basin linkages (including those lagged in time) are not built-in to the analysis protocol. Similarly, we analyze monthly data (lightly smoothed with a 3-point running mean) so as to avoid artificially building in any low-frequency behavior. In this regard, it is important to bear in mind the null hypothesis that any low-pass filtered time series will exhibit DCV, but it need not be physically meaningful (i.e., it may not be distinguishable from a random process).

We use the NOAA Extended Reconstruction Sea Surface Temperature, version 3b (ERSSTv3b) dataset, which employs a statistical procedure on the ICOADS data to fill in missing grid boxes (Smith et al., 2008); other data sets yield similar results (not shown). Following previous studies, we subtract the global mean SST anomaly (SSTA) from the SSTA at each grid box for each month and year (hereafter, we use the nomenclature SSTA* to denote this residual from the global mean) unless noted otherwise. This procedure is intended to remove any secular global trends that may be associated with changes in external radiative forcing such as those due to human-induced increases in greenhouse gas concentrations and sulfate aerosols accompanying fossil fuel burning. We shall return to the issue of how well this procedure achieves its intended purpose in Section 5.

We define the main phenomena of DCV for each basin separately as follows. North Pacific (NPAC): leading principal component (PC) time series of monthly SSTA* over the domain $\left(20^{\circ}-70^{\circ} \mathrm{N}, 110^{\circ} \mathrm{E}-100^{\circ} \mathrm{W}\right)$ following Mantua et al. (1997). North Atlantic (NATL): time series of SSTA* averaged over the domain $\left(0^{\circ}-60^{\circ} \mathrm{N}, 80^{\circ} \mathrm{W}-0^{\circ} \mathrm{W}\right)$ following Trenberth and Shea (2006). Southern Ocean (SO): time series of SSTA (not SSTA*) averaged over the domain $\left(50^{\circ}-70^{\circ} \mathrm{S}, 0^{\circ} \mathrm{W}-360^{\circ} \mathrm{E}\right)$ following Fan et al. (2014). We have inverted the SO time series to facilitate comparison with NPAC and NATL. These regions are outlined in Fig. 1c. To obtain the global-scale patterns associated with each time series, we regress SSTA* (SSTA for the case of the SO) at each grid box on the standardized index time series.

Before showing the spatial patterns of DCV, we return to the issue of data coverage. The right-hand panels of Fig. 1 show time series of data coverage in each region defined above, represented as the percentage of grid boxes that have at least one observation in each month. Consistent with the data coverage maps, the NPAC region shows $>50 \%$ of grid boxes with at least one observation starting around 1920 except during the 1940s (Fig. 1d). The NATL region shows $>50 \%$ of grid boxes present since about 1885 except for the World Wars and around 1900 (Fig. $1 \mathrm{e}$. Finally, coverage in the SO region is always $<40 \%$, and $<10 \%$ before 1950 (Fig. 1f). A large seasonal cycle is evident in the SO region, with peak coverage during summer (Fan et al., 2014). In view of these results, we choose to show the NPAC and NATL time series starting in 1890 (mindful of the reduced coverage in NPAC before 1920 ), and the SO record starting in 1950 . However, the global regression maps are all based on the period since 1950 to accommodate the lack of data over the Southern Ocean (and to a lesser extent, the Tropical Pacific) before that time.

The three SSTA* patterns show a great deal of similarity in their global structures, despite that they are based on different index regions. For example, NPAC shows a pan-Indo/Pacific pattern with symmetry about the equator, reminiscent of the low-frequency "tail" of ENSO (also termed the "Pacific Decadal Oscillation PDO or "Inter-Decadal Pacific Oscillation IPO) (Zhang et al., 1997; Power et al., 1999; Vimont, 2005; Newman et al., 2016). It also features linkages to the Atlantic in the form of alternating polarities with latitude, with positive values over the northern North Atlantic, and negative values over the Pacific sector of the Southern Ocean (Fig. 2a). NATL exhibits an out-of-phase relationship between SSTA* in the North and South Atlantic, distinct from that based on NPAC (Fig. 2b). However, it shares the same SSTA* polarity over the northern NATL and the same PDO-like structure, albeit with weaker magnitude, as that based on NPAC, and it shows negative values throughout the Southern Ocean (Fig. 2b).
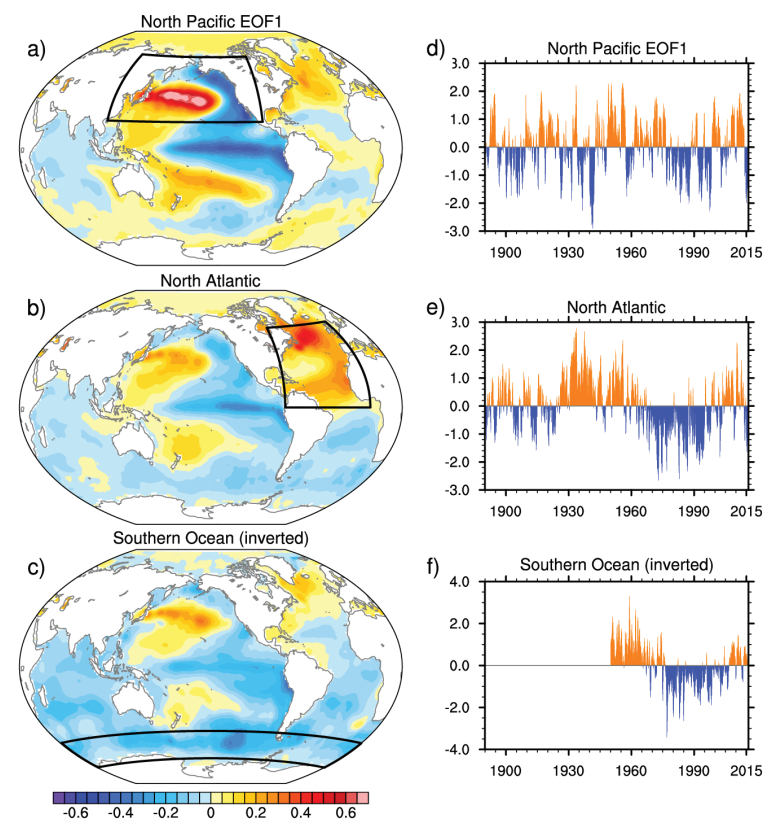

Figure 2: Spatial and temporal characteristics of sea surface temperature anomaly (SSTA) variability in selected ocean basins. (Left column) Global SSTA* regression maps (degrees C) based on the (a) leading principal component of North Pacific SSTA*, (b) North Atlantic SSTA*, and (c) inverted Southern Ocean SSTA. All indices were standardized prior to computing the regression maps. Index regions are outlined by black boxes. (Right column) Standardized 3-month running mean time series (1880-2015) of the (a) leading principal component of North Pacific SSTA*, (b) North Atlantic SSTA*, and (c) inverted Southern Ocean SSTA. Asterisk indicates that the global mean SSTA was removed prior to computing the time series and regression maps. 
Finally, the pattern based on the (inverted) SO index is very similar to that based on NATL, except for the sign over the northern tropical Atlantic (Fig. 2c).

The NPAC, NATL and SO index time series are remarkably similar during their period of overlap (1950-2015), with pronounced decadal-scale variability evident even in 3-month running mean data (Figs. 2d-f). In particular, each record swings from positive to negative and back to positive during 1950-2015, with a suggestion that NATL leads NPAC and SO by 10-20 years. Before 1950, NPAC shows less prominent decadal-scale variability and a weaker relationship with NATL than after 1950. We refrain from quantifying these statements due to the low number of degrees of freedom associated with such short records of DCV.

\section{Causes of DCV}

The substantial degree of commonality in the global-scale patterns associated with Pacific, Atlantic and Southern Ocean DCV, combined with the fact that they are based on short records and sparse sampling, make it challenging to identify these phenomena robustly in terms of spatial and temporal character. These constraints also make it difficult to assess whether they arise from distinctive dynamical processes operating on decadal time scales and/or whether they are best viewed as manifestations of a "random walk" process or processes (see also Newman et al., 2016). The concept of global-scale SSTA "hypermodes" (Dommenget and Latif, 2008; Dommenget, 2010; Clement et al., 2011) has been advanced to account for the similarity of global-scale SSTA patterns regardless of how they originate. This concept relies on the notion that the lower the frequency, the more global the pattern, due to the interplay between SSTA and the large-scale atmospheric circulation.

These issues highlight the need for a combined approach based on observations, paleo-climate records and modeling to delineate robust phenomena of DCV and to understand their causes. Indeed, modeling studies based on thousands of years of simulation for robust statistics suggest that Atlantic DCV and its globalscale teleconnections may originate from the mutual interaction of the oceanic Atlantic Meridional Overturning Circulation (AMOC) and the large-scale atmospheric circulation in the form of the North Atlantic Oscillation (NAO) (Delworth et al., 2016; Delworth and Zeng, 2016; Ruprich-Robert et al., 2016), although the mechanisms continue to be under investigation. Similar conclusions arise for Southern Ocean DCV (Latif et al, 2013; Latif et al., 2015; Zhang et al., 2016). Finally, Pacific DCV may reflect a combination of stochastic processes, each with a different decorrelation time scale and regional emphasis arising from dynamical and thermodynamic air-sea interaction (Clement et al., 2011; Okumura, 2013; Newman et al., 2016).

\section{Internal vs. externally-forced DCV}

As mentioned above, DCV is traditionally identified as the residual from the global mean SSTA; the latter interpreted as the secular fingerprint of human-induced climate change. However, human-induced climate change is not spatially uniform (Xie et al., 2010) and thus the removal of the global-mean SSTA may fall short of its intended purpose. The validity of this approach can be tested with large initial-condition ensembles of historical simulations with comprehensive coupled climate models, such as 40-member Community Earth System Model Large Ensemble (CESM-LE) (Kay et al., 2015). The CESM-LE has been used to isolate externally-forced and internally-generated components of simulated NATL DCV, with implications for observed NATL DCV (Tandon and Kushner, 2015; Murphy et al., 2016). These studies indicate that a significant portion of NATL DCV since 1920 may be externally-forced, and that empirical methodologies used to separate these components in the single observational record may be inadequate. Further work is needed to evaluate the efficacy of empirical approaches for separating forced and internal components of DCV, not only in the NATL but in other ocean basins as well. These approaches include linear (or other forms of) detrending, removal of the globalmean, optimal fingerprinting (Ting et al., 2009; Ting et al., 2014), pattern scaling (Hoerling et al., 2011; Bichet et al., 2015), and Empirical Ensemble Mode Decomposition (Wu et al., 2011).

\section{Concluding remarks}

We have presented a brief overview of the main phenomena of DCV based on simple analyses of observed SST over the historical record using a basin-specific approach. Our results indicate that DCV is apparent even in unfiltered seasonal data, and that DCV in the North Atlantic, North Pacific and Southern Ocean share many characteristics including their global-scale patterns and chronologies, especially since 1950. Results are more ambiguous before that time. Given the shortness of the observational record relative to the time scales of interest, we believe that DCV is best viewed in terms of a case study approach rather than as a robust and stationary statistical characterization. Long (thousands of years) model control simulations provide an effective tool for assessing the robustness and global-scale linkages of DCV, provided the model has a credible representation of the relevant processes governing DCV. Finally, an outstanding research question is the extent to which DCV is externally-forced vs. internally-generated.

\section{References}

Bichet, A., P. Kushner, L. Mudryk, L. Terray, and J. Fyfe, 2015: Estimating the Anthropogenic Sea Surface Temperature Response Using Pattern Scaling. J. Climate, 28,3751-3763, doi: 10.1175/JCLI-D-14-00604.1.

Clement, A., P. DiNezio, and C. Deser, 2011: Rethinking the 
Ocean's Role in the Southern Oscillation. J. Climate, 24, 4056-4072, doi: 10.1175/2011JCLI3973.1.

Delworth, T. L., F. Zeng, L. Zhang, R. Zhang, G. A. Vecchi1 and X. Yang, 2016: The central role of ocean dynamics in connecting the North Atlantic Oscillation to the Atlantic Multidecadal Oscillation, J. Climate, in press.

Delworth, T. L. and F. Zeng, 2016: The impact of the North Atlantic Oscillation on climate through its impact on the Atlantic Meridional Overturning Circulation. J. Climate. DOI: 10.1175/JCLI-D-15-0396.1

Deser, C., M. A. Alexander, S. -P. Xie, and A. S. Phillips, 2010: Sea surface temperature variability: patterns and mechanisms. Ann. Rev. Mar. Sci., 2010.2, 115-143, doi:10.1146/annurev-marine-120408-151453.

Dommenget, D. and M. Latif, 2008: Generation of hyper climate modes. Geophys. Res. Lett., 35, L02706, doi:10.1029/2007GL031087.

Dommenget, D., 2010: A slab ocean El Nino. Geophys. Res. Lett., 37, L20701, doi:10.1029/2010GL044888.

Fan, T., C. Deser, and D. P. Schneider, 2014: Recent Antarctic sea ice trends in the context of Southern Ocean surface climate variations since 1950 . Geophys. Res. Lett., 41, 2419-2426, doi:10.1002/2014GL059239.

Hoerling, M., J. Hurrell, A. Kumar, L. Terray, J. Eischeid, P. Pegion, T. Zhang, X. Quan, and T. Y. Xu, 2011 (August): On North American decadal climate for 2011-20. J. Climate, 24, 4519-4528.

doi:10.1175/2011JCLI4137.1

Kay, J. E., C. Deser, A. Phillips, and co-authors, 2015: The Community Earth System Model (CESM) Large Ensemble Project: A community resource for studying climate change in the presence of internal climate variability. Bull. Amer. Met. Soc., 96, 1333-1349, doi: 10.1175/ BAMS-D-13-00255.1.

Latif, M., T. Martin and W. Park, 2013: Southern Ocean sector centennial climate variability and recent decadal trends. J. Climate, 26, 7767-7782. DOI: 10.1175/ JCLI-D-12-00281.1.

Latif, M., T. Martin, W. Park, and M. Bordbar, 2015: Internal Southern Ocean Centennial Variability: Dynamics, Impacts and Implications for Global Warming. In Climate Change: Multidecadal and Beyond, pp.109-124.

DOI:10.1142/9789814579933_0007.

Mantua, N. J., S. R. Hare, Y. Zhang, J. M. Wallace, and R. C. Francis, 1997: A Pacific Interdecadal Climate Oscillation with Impacts on Salmon Production. Bull. Amer. Meteor. Soc, 78, 1069-1079.
Murphy, L. N., K. Bellomo, M. Cane and A. Clement, 2016: The Role of Historical Forcings in Simulating the Observed Atlantic Multidecadal Oscillation. Geophys. Res. Lett., in review.

Newman, M., M. A. Alexander, T. R. Ault, K. M. Cobb, C. Deser, E. Di Lorenzo, N. J. Mantua, A. J. Miller, S. Minobe, H. Nakamura, N. Schneider, D. J. Vimont, A. S. Phillips, J. D. Scott, and C. A. Smith, 2016: The Pacific decadal oscillation, revisited. J. Climate, in press. doi: 10.1175/ JCLI-D-15-0508.1.

Okumura, Y. M., 2013: Origins of tropical Pacific decadal variability: Role of stochastic atmospheric forcing from the South Pacific. J. Climate 26 (24), 9791-9796.

Power, S., T. Casey, C. Folland, A. Colman, and V. Mehta, 1999: Inter-decadal modulation of the impact of ENSO on Australia. Clim Dyn, 15, 319-324, doi:10.1007/ s003820050284.

Ruprich-Robert, Y., R. Msadek, F. Castruccio, S. Yeager, T. Delworth, and G. Danabasoglu, 2016: Assessing the Climate impacts of the observed Atlantic Mulitdecadal Variability using the GFDL CM2.1 and NCAR CESM1 Global Coupled Models. J. Climate, in press. doi: 10.1175/JCLI-D-16-0127.1.

Smith, T. M., R. W. Reynolds, T. C. Peterson, and J. Lawrimore, 2008: Improvements to NOAA's historical merged land-ocean surface temperature analysis (18802006). J. Climate, 21, 2283-2296.

DOI: $10.1175 / 2007 J C L I 2100.1$

Tandon, N.F., and P.J. Kushner, 2015: Does External Forcing Interfere with the AMOC's

Influence on North Atlantic Sea Surface Temperature? J. Climate, 28, 6309-6323. DOI:10.1175/JCLI-D-14-00664.1

Ting, M., Kushnir, Y., Seager, R., Li, C., 2009: Forced and internal twentieth-century SST in the North Atlantic. J. Climate, 22, 1469-1481.

Ting, M., Kushnir, Y., Li, C., 2014: North Atlantic Multidecadal SST Oscillation: External forcing versus internal variability, Journal of Marine Systems, 133, 2738.

Trenberth, K. E., and D. J. Shea, 2006: Atlantic hurricanes and natural variability in 2005. Geophys. Res. Lett., 33, L12704, doi:10.1029/2006GL026894.

Vimont, D. J. 2005: The contribution of the interannual ENSO cycle to the spatial pattern of decadal ENSO-like variability. J. Climate, 18, 2080-2092.

Woodruff, S. D., and co-authors, 2008: The evolving SST record from ICOADS, in Climate Variability and Extremes 
During the Past 100 Years, Adv. Global Change Res., vol. 33, edited by S. Brönnimann et al., pp. 65-83, Springer, New York.

Wu Z, Huang NE, Wallace JM, Smoliak BV, Chen X., 2011: On the time-varying trend in global-mean surface temperature. Clim Dyn 37:759-773.

Xie, S. -P., C. Deser, G. A. Vecchi, J. Ma, H. Teng, A. T. Wittenberg, 2010: Global warming pattern formation: sea surface temperature and rainfall. J. Climate, 23, 966986, doi:101175/2009JCLI3329.1.

Zhang, L., T. L. Delworth, and F. Zeng, 2016: The impact of multidecadal Atlantic meridional overturning circulation variations on the Southern Ocean. Clim. Dyn., DOI 10.1007/s00382-016-3190-8.

Zhang, Y., J. M. Wallace, and D. S. Battisti, 1997: ENSO-like interdecadal variability: 1900-93. J. Climate, 10, 10041020. 